Article

\title{
Designing Functionally Versatile, Highly Immunogenic Peptide-Based Multiepitopic Vaccines against Foot-and-Mouth Disease Virus
}

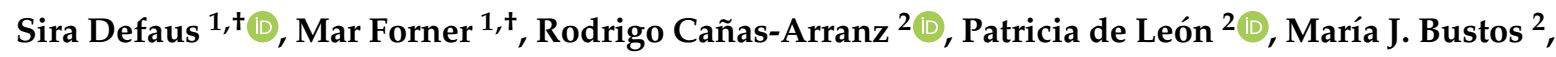 \\ Miguel Rodríguez-Pulido ${ }^{2}\left(\mathbb{D}\right.$, Esther Blanco ${ }^{3}{ }^{(\mathbb{D}}$, Francisco Sobrino ${ }^{2, *}(\mathbb{D})$ and David Andreu ${ }^{1, *}$ \\ 1 Departament de Ciències Experimentals i de la Salut, Universitat Pompeu-Fabra, 08003 Barcelona, Spain; \\ sira.defaus@upf.edu (S.D.); mar.forner@upf.edu (M.F.) \\ 2 Centro de Biología Molecular “Severo Ochoa” (CSIC-UAM), 28049 Madrid, Spain; \\ rcannas@cbm.csic.es (R.C.-A.); pdeleon@cbm.csic.es (P.d.L.); mjbustos@cbm.csic.es (M.J.B.); \\ mrrodriguez@cbm.csic.es (M.R.-P.) \\ 3 Centro de Investigación en Sanidad Animal (CISA-INIA), Valdeolmos, 28130 Madrid, Spain; blanco@inia.es \\ * Correspondence: fsobrino@cbm.csic.es (F.S.); david.andreu@upf.edu (D.A.) \\ + These authors contributed equally to this work.
}

Received: 27 May 2020; Accepted: 16 July 2020; Published: 22 July 2020

check for updates

\begin{abstract}
A broadly protective and biosafe vaccine against foot-and-mouth disease virus (FMDV) remains an unmet need in the animal health sector. We have previously reported solid protection against serotype O FMDV afforded by dendrimeric peptide structures harboring virus-specific B- and T-cell epitopes, and also shown such type of multivalent presentations to be advantageous over simple B-T-epitope linear juxtaposition. Chemically, our vaccine platforms are modular constructions readily made from specified B- and T-cell epitope precursor peptides that are conjugated in solution. With the aim of developing an improved version of our formulations to be used for on-demand vaccine applications, we evaluate in this study a novel design for epitope presentation to the immune system based on a multiple antigen peptide (MAP) containing six immunologically relevant motifs arranged in dendrimeric fashion (named $\mathrm{B}_{2} \mathrm{~T}-\mathrm{TB}_{2}$ ). Interestingly, two $\mathrm{B}_{2} \mathrm{~T}$ units fused tail-to-tail into a single homodimer platform elicited higher B- and T-cell specific responses than former candidates, with immunization scores remaining stable even after 4 months. Moreover, this macromolecular assembly shows consistent immune response in swine, the natural FMDV host, at reduced dose. Thus, our versatile, immunogenic prototype can find application in the development of peptide-based vaccine candidates for various therapeutic uses using safer and more efficacious vaccination regimens.
\end{abstract}

Keywords: peptide-based vaccines; foot-and-mouth disease virus; multivalency; click chemistry; swine host

\section{Introduction}

Foot-and-mouth disease (FMD), a highly contagious viral disease of cloven-hoofed animals, persists as a threat for livestock production in both endemic and allegedly "free" countries. The disease is currently present in regions of Africa, Middle East, and Asia. Among the methods recommended by the World Organization for Animal Health (OIE) for FMD control and eradication, chemically inactivated virus-derived vaccines are still in wide use [1-3]. However, such conventional vaccines have serious limitations such as (i) the risk of virus escape during vaccine preparation, (ii) extensive genetic and antigenic variability, illustrated by the existence of seven different serotypes and many variants, (iii) difficulties for serological distinction between infected and vaccinated animals (DIVA concept), and (iv) the requirement for cold chain logistics to preserve vaccine stability $[4,5]$. These drawbacks, 
together with the fatal consequences of FMDV sporadic but still severe outbreaks [6-8], evince the need for better FMD countermeasure policies. In this regard, subunit vaccines devoid of infectious agent, particularly those based on synthetic peptides, have arisen as an attractive alternative due to their multiple advantages including safety, marker nature, fine-tuning to different strains, and easy handling, shipping and storage $[9,10]$.

Although peptides are able to replicate well-known antigenic epitope motifs [11,12] of an entire virus, early attempts of FMD vaccination using recognized linear B-cell peptide epitopes induced only limited protection in natural hosts [13-16]. A deeper understanding of the cellular and molecular mechanism underpinning immunogenic responses has contributed to the currently prevailing idea that the protective immune response to a vaccine is not only due to the presence of circulating antibodies via B-cell activation (humoral immunity), but also due to the actions of sensitized T-lymphocytes (cell-mediated immunity) [17-20]. In this context, T-cell epitopes efficiently recognized by $\mathrm{T}$ lymphocytes from different animals upon heterotypic FMDV infection have been identified, thus extending the repertoire of viral T-cell epitopes to be considered for FMDV subunit and synthetic vaccine strategies [21-24]. Apart from the inclusion of an adequate T-cell epitope in the vaccine formulation, T- and B-cell epitope orientation and multiplicity are also decisive factors for developing successful peptide-based vaccine candidates [25-27]. In tune with this, we first reported a dendrimeric peptide consisting of one copy of a T-cell epitope conjugated in branched fashion to four copies of a B-cell epitope (serotype C) [28] as capable of inducing high levels of protective mucosal IgA response in domestic pigs infected with FMDV [29]. Remarkably, a bivalent dendrimer version bearing the same T-cell epitope conjugated to two copies of the B-cell epitope (serotype O) elicited even better results [30], and a similar construct displaying B-cell epitopes from classical swine fever virus (CSFV) also showed humoral response [31] in pigs. These results supported the relevant cooperative role of the T-cell epitope inducing neutralizing response against different viruses. Subsequently, different ligation strategies were explored pointing out to a $\mathrm{B}_{2} \mathrm{~T}$ platform made via maleimide conjugation as a highly valuable, cost-effective FMDV vaccine candidate providing full and longer protection of vaccinated animals after viral challenge [30,32].

Taken together, all these attempts along with other reported examples [33-35] reinforce multivalence as an extremely powerful concept having also a positive impact on the immunogenicity of synthetic vaccine prototypes. Indeed, dendrimer research has a strong impact on a broad range of biotech fields, as shown by the spectacular growth in the number of related publications [36]. While the potential applications of these multivalent presentations with their highly customizable properties are plentiful, some of their current uses relevant to vaccinology are still scarce. In this study, advances in the potential of spatially diverse architectures on the in vivo biological response of dendrimers as subunit vaccines against FMDV, as well as recent progress in design-driven optimization of this new generation of multiepitope bioconjugate vaccines against FMDV, are presented.

\section{Materials and Methods}

\subsection{Reagents and Analytical Procedures}

Fmoc-protected amino acids and HBTU were from Iris Biotech (Marktredwitz, Germany). Fmoc-Rink-amide ChemMatrix resin was from PCAS Bio-Matrix, Inc. (Saint-Jean-sur-Richelieu, $\mathrm{QC}$, Canada). HPLC-grade $\mathrm{CH}_{3} \mathrm{CN}$ and peptide-synthesis-grade $\mathrm{DMF}, \mathrm{CH}_{2} \mathrm{Cl}_{2}$, DIEA, and TFA were from Carlo Erba-SdS (Sabadell, Spain) and/or Fisher Scientific International, Inc. (Pittsburgh, PA, USA). All other reagents were of the highest quality commercially available from Sigma-Aldrich (Madrid, Spain). Analytical reversed-phase HPLC was performed on C18 columns $(4.6 \times 50 \mathrm{~mm}, 3 \mu \mathrm{m}$, Phenomenex, Torrance, CA, USA) in a model LC-2010A system (Shimadzu, Kyoto, Japan). Solvent A was $0.045 \%(v / v)$ TFA in water; solvent $\mathrm{B}$ was $0.036 \%(v / v)$ TFA in $\mathrm{CH}_{3} \mathrm{CN}$. Elution was done with linear 20-60\% gradients of solvent B into A over $15 \mathrm{~min}$ at $1 \mathrm{~mL} / \mathrm{min}$ flow rate, with UV detection at $220 \mathrm{~nm}$. Preparative HPLC was performed on C18 $(10 \times 250 \mathrm{~mm}, 10 \mu \mathrm{m}$, Phenomenex $)$ in a Shimadzu LC-8A 
instrument. Solvents $\mathrm{A}$ and $\mathrm{B}$ were $0.1 \% \mathrm{TFA}(\mathrm{v} / \mathrm{v})$ in water and $\mathrm{CH}_{3} \mathrm{CN}$, respectively, and elution was again with linear gradients of solvent B into A over $20 \mathrm{~min}$, at $5 \mathrm{~mL} / \mathrm{min}$ flow rate with UV detection at $220 \mathrm{~nm}$. Fractions of satisfactory purity (>95\%) by analytical HPLC were pooled and lyophilized. Purified peptides and conjugates were characterized for identity by ESI-MS with an LCMS-2010 EV mass spectrometer (Shimadzu, Kyoto, Japan) controlled using LabSolutions LCMS software and/or by MALDI-TOF MS in a ABSciex 4800 Plus spectrometer (Applied Biosystems, Foster City, CA, USA), using $\alpha$-cyano-4-hydroxycinnamic acid as matrix.

\subsection{General Peptide Synthesis Procedures}

Linear peptides were assembled in a Prelude synthesizer (Protein Technologies, Inc., Tucson, AZ, USA) running Fmoc SPPS protocols at $0.1 \mathrm{mmol}$ scale on Fmoc-Rink-amide ChemMatrix resin. The side chain functionalities were protected with tertbutyl (Asp, Glu, Ser, Thr, Tyr), tert-butyloxycarbonyl (Lys, Trp), NG-2,2,4,6,7-pentamethyldihydrobenzofuran-5-sulfonyl (Arg), and trityl (Asn, Gln, His) groups. Eight-fold excess of Fmoc-L-amino acids and HBTU, in the presence of a double molar amount of DIEA, were used for the coupling steps, with DMF as solvent. All peptides were fully deprotected and cleaved from the resin with TFA $/ \mathrm{H}_{2} \mathrm{O} /$ triisopropylsilane (95:2.5:2.5 v/v, $90 \mathrm{~min}$, r.t.), precipitated by addition of chilled diethyl ether, taken up in aqueous $\mathrm{AcOH}$ $(10 \% v / v)$, and lyophilized. Reverse-phase HPLC purification gave homogeneous materials with the expected mass by LC-MS.

\subsection{Functionalization and Conjugation of Peptides}

Peptides reproducing the B- and T-cell epitopes of FMDV O UKG/11/2001 in different arrangements are shown in Figure 1. All peptides were made from precursors prepared by solid phase synthesis and purified prior to conjugation as previously specified. In all cases, branching was achieved by $\mathrm{T}$ epitope N-terminal elongation with two Lys units followed by either three $\left[\mathrm{B}_{4} \mathrm{~T}(\right.$ thi $\left.)\right]$ or one $\left[\mathrm{B}_{2} \mathrm{~T}(\mathrm{mal})\right]$ additional Lys in a branched arrangement. To allow conjugation, $\mathrm{T}$ epitope was functionalized with chloroacetyl $\left[\mathrm{B}_{4} \mathrm{~T}(\right.$ thi) $]$ or maleimido $\left[\mathrm{B}_{2} \mathrm{~T}(\mathrm{mal})\right]$ groups, and an $N$-acetylated B epitope with a C-terminal Cys whose free thiol group reacts with either chloroacetyl or maleimide units. For $\mathrm{B}_{2} \mathrm{~T}-\mathrm{TB}_{2}$ (click) synthesis, tail-to-tail fusion of two units of $\mathrm{B}_{2} \mathrm{~T}(\mathrm{mal})$ peptide was accomplished by further functionalization of T epitope at the C-terminal with either an azide- or an alkyne-containing non-canonical amino acid and those end groups finally reacting via CuAAC. Additional details on the synthesis are available in refs $[30,37]$. The final products were purified to near homogeneity by HPLC and characterized by MS.

\subsection{Animal Immunizations}

The immune response to $\mathrm{B}_{2} \mathrm{~T}(\mathrm{mal}), \mathrm{B}_{4} \mathrm{~T}\left(\right.$ thi), and $\mathrm{B}_{2} \mathrm{~T}_{-} \mathrm{TB}_{2}$ (click) dendrimeric peptides was assessed in outbred Swiss ICR-CD1 mice (Harlan Laboratories, Boxmeer, The Netherlands) and/or domestic Landrace X Large White pigs (Agropardal SL, Almendros, Cuenca, Spain), free of antibodies against FMDV. Animals were maintained under standard housing conditions in the CBMSO (mice) and Departamento de Reproducción Animal, INIA (pigs). Animal facilities and experimental procedures were conducted in accordance with protocols approved by CSIC and INIA Committees on Ethics of Animal Experiments and Biosafety, as well as of the National Committee on Ethics and Animal Welfare (PROEX 034/15 at CBMSO; PROEX 218/14, PROEX 47/13 and PROEX 214/15 at INIA).

Female mice (5-9 weeks old) in groups of five received a primary immunization (day 0 ) followed by a booster dose on day 21 , by subcutaneous route, with $100 \mu \mathrm{g}$ of each conjugated dendrimeric peptide emulsified in Montanide ISA-50 V2 (Seppic, Puteaux, France). Serum samples were collected by mandibular bleeds on days 0,21 , and 40 . The animals were humanely sacrificed on day 40.

Two month-old pigs were randomly assigned to three groups of four animals each. The pigs received a primary immunization (day 0) followed by a booster dose on day 39, by intramuscular route with $2 \mathrm{~mL}$ of an emulsion containing 2 or $0.5 \mathrm{mg}$ of dendrimer $\mathrm{B}_{2} \mathrm{~T}(\mathrm{mal})$ or $\mathrm{B}_{2} \mathrm{~T}_{-} \mathrm{TB}_{2}(\mathrm{click})$ in Montanide oil ISA-50 V2. Two additional pigs inoculated with a mock emulsion prepared using PBS 
and adjuvant were kept as infection controls. Blood samples were collected at days $0,7,14,21,28,91$, 127, and 154 pi to obtain serum and peripheral blood mononuclear cells (PBMCs).

A)

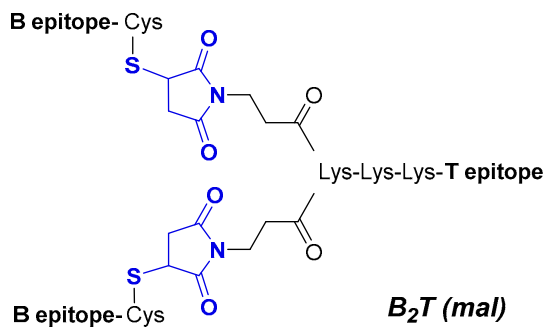

B)

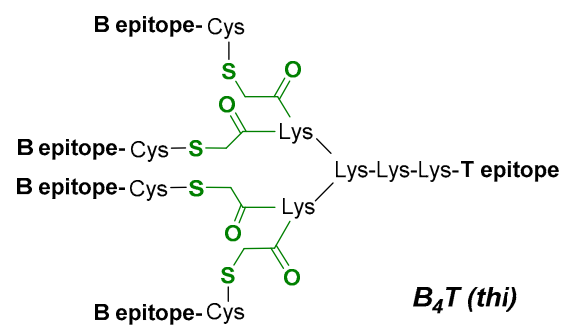

C)

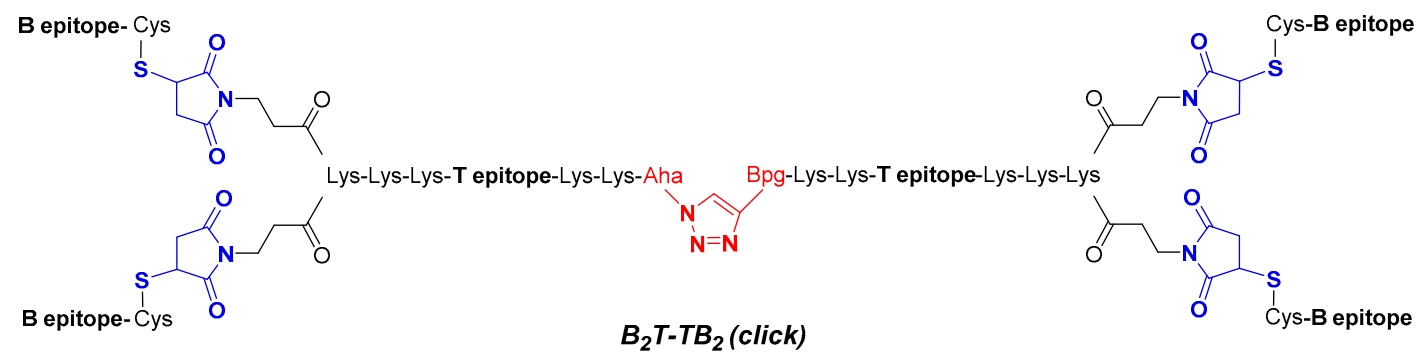

Figure 1. Conjugation approaches to dendrimeric immunogens based on lysine-branched constructs containing B- and T-cell epitopes of foot-and-mouth disease virus (FMDV) O UKG/11/2001 in a 2:1 (A), 4:1 (B) or 4:2 (C) ratio; the Lys-Lys motif in each construct is a putative cathepsin D cleavage site. Different chemical ligations strategies were employed to connect the epitopes, including maleimide (blue), thioether (green), and triazole (red) linkages.

\subsection{Detection of Specific Anti-FMDV Antibodies by ELISA}

Total anti-FMDV antibodies were determined by ELISA. Briefly, 96-well plates (Nunc) were coated with B peptide $(1 \mu \mathrm{g})$ overnight at $4{ }^{\circ} \mathrm{C}$. Duplicate three-fold dilution series of each serum sample were prepared in $50 \mu \mathrm{L}$, starting at $1 / 100$. Pre-immune sera from peptide-immunized animals and sera from non-immunized animals were used as negative controls. Specific antibodies were detected with HRP-conjugated protein A (Thermo Fisher, Waltham, MA, USA), diluted 1/4000. Color development was obtained after addition of $100 \mu \mathrm{L} /$ well of TMB (Sigma Aldrich) and stopped by an equal volume of $\mathrm{H}_{2} \mathrm{SO}_{4} 1 \mathrm{M}$. Plates were read at $450 \mathrm{~nm}$ and titers in a $\log 10$ scale were expressed as the reciprocal of the last dilution giving the absorbance recorded in the control wells (serum at day 0) plus 2 SD.

\subsection{Virus Neutralization Test (VNT)}

Serial two-fold dilutions of sera were incubated with 100 infection units- $50 \%$ tissue culture infective doses (TCID50) - of FMDV O UKG/11/2001, for $1 \mathrm{~h}$ at $37^{\circ} \mathrm{C}$. Then, a cell suspension of IBRS-2 cells in DMEM was added and plates were incubated for $72 \mathrm{~h}$. Monolayers were controlled for development of cytopathic effect (cpe), fixed and stained. End-point titers in a log10 scale were calculated as the reciprocal of the serum dilution that neutralized FMDV infection in 50\% of the wells [30].

\subsection{PBMCS Isolation and IFN- $\gamma$ Detection by ELISPOT}

Porcine peripheral blood mononuclear cells (PBMCs) were isolated by density gradient centrifugation using Histopaque-1077 (Sigma-Aldrich, St. Louis, MO, USA). Cell counting and viability were tested by trypan blue staining. For the IFN- $\gamma$ ELISPOT assay $2.5 \times 10^{5}$ PBMCs were shed in triplicate wells of Immobilon-P plates (Merck Millipore, Madrid, Spain) coated with $5 \mu \mathrm{g} / \mathrm{mL}$ of anti-pig 
IFN- $\gamma$ antibody (clone P2G10, BD Biosciences, San Agustín de Guadalix, Madrid, Spain). For in vitro antigen recall, PBMCs were stimulated with $50 \mu \mathrm{g} / \mathrm{mL}$ of the peptide used for pig immunization [38]. As positive control, $\mathrm{PBMCs}$ were incubated with $10 \mu \mathrm{g} / \mathrm{mL}$ of phytohaemagglutinin (Sigma-Aldrich, St. Louis, MO, USA) using cells incubated without antigen as negative control. After $48 \mathrm{~h}$ at $37^{\circ} \mathrm{C}-5 \%$ $\mathrm{CO}_{2}$, plates were washed and incubated with $2 \mu \mathrm{g} / \mathrm{mL}$ of biotinylated anti-mouse IFN- $\gamma$ antibody (clone P2C11, BD Biosciences) and HRP-streptavidin (BD Biosciences). Antibody was visualized with 3-amino-9-ethyl carbazole (BD Biosciences). The frequency of peptide-specific T-cells was expressed as the mean number of spot-forming cells $/ 10^{6}$ PBMCs, with background values (number of spots in negative control wells) subtracted from the respective counts of stimulated cells.

\subsection{Statistical Analyses}

Differences among peptide-immunized groups in FMDV-antibody titers and number of IFN- $\gamma$ producing cells, were analyzed by one-way ANOVA, followed by Tukey's post-hoc comparisons tests. Values are cited in the text as means $\pm \mathrm{SD}$. All $p$ values are two sided, and $p$ values $<0.05$ were considered significant. Statistical analyses were conducted using GraphPad Prism Software 5.0 (San Diego, CA, USA).

\section{Results and Discussion}

\subsection{Dendrimeric Peptide-Based FMD Candidate Vaccine Preparation}

Three different multivalent constructs (i.e., $\mathrm{B}_{2} \mathrm{~T}(\mathrm{mal}), \mathrm{B}_{4} \mathrm{~T}(\mathrm{thi})$ and $\mathrm{B}_{2} \mathrm{~T}_{-} \mathrm{TB}_{2}$ (click)) were synthesized using a branched lysine core matrix from which various arrangements exploiting both alpha $(\alpha)$ and epsilon $(\varepsilon)$ reactive amino groups in Lys residues were implemented. Although with different scaffold presentations, all dendrimers in this study were composed of linear peptide modules replicating either B- or T-cell relevant epitopes derived from FMDV serotype O UKG/11/2001, specifically the VP1(140-158) and 3A(21-35) sequences (Table 1). In all constructs a Lys-Lys dipeptide motif was included to define a cleavage site for cathepsin $\mathrm{D}$, a protease putatively involved in in vivo antigen processing for presentation to the MHC class II molecules [39]. Given the different frameworks designed, several linking functionalities were used at various parts of the peptide building blocks, to carry out the corresponding conjugation strategies (Figure 1).

Table 1. Peptide-based vaccine candidates.

\begin{tabular}{|c|c|c|c|}
\hline General Name & $\mathrm{B}_{2} \mathrm{~T}$ (Mal) & $\mathrm{B}_{4} \mathrm{~T}$ (Thi) & $\mathrm{B}_{2} \mathrm{~T}_{-} \mathrm{TB}_{2}$ (Click) \\
\hline General structure $^{a}$ & 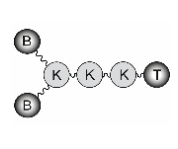 & 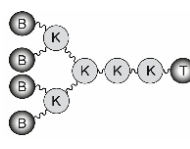 & 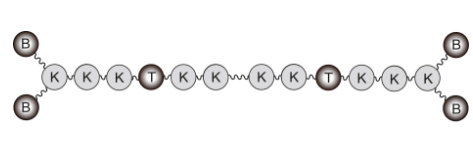 \\
\hline $\begin{array}{l}\text { MW }{ }^{\mathrm{b}} \\
\text { HPLC }^{\mathrm{c}}\end{array}$ & $\begin{array}{c}6742.8 \mathrm{Da} \\
6.9 \mathrm{~min}(98 \%)\end{array}$ & $\begin{array}{c}11,204.1 \mathrm{Da} \\
7.1 \mathrm{~min}(95 \%)\end{array}$ & $\begin{array}{c}14,247.6 \mathrm{Da} \\
7.9 \mathrm{~min}(97 \%)\end{array}$ \\
\hline $\begin{array}{l}\text { B epitope } \\
\text { T epitope }\end{array}$ & \multicolumn{3}{|c|}{$\begin{array}{l}\text { acetyl-PVTNVRGDLQVLAQKAARTC-amide } \\
\text { AAIEFFEGMVHDSIK-amide }\end{array}$} \\
\hline
\end{tabular}

${ }^{a} B_{n} T_{n}$ construct with $n$ B epitope copies linked to a T epitope in different dendrimeric architectures. ${ }^{b}$ Experimental peptide mass obtained by LC/MS. ${ }^{c}$ Retention time on a C18 column (Luna, $4.6 \mathrm{~mm} \times 50 \mathrm{~mm}, 3 \mathrm{~mm}$; Phenomenex) eluted with a $20-60 \%$ linear gradient of solvent B $\left(0.036 \%\right.$ TFA in MeCN) into solvent A $\left(0.045 \%\right.$ TFA in $\left.\mathrm{H}_{2} \mathrm{O}\right)$ over $15 \mathrm{~min}$. In parenthesis, HPLC homogeneity of purified material.

\subsubsection{Bivalent-Branched $\mathrm{B}_{2} \mathrm{~T}$ Conjugate $\left[\mathrm{B}_{2} \mathrm{~T}(\mathrm{mal})\right]$}

A practical route to $B_{2}$ T-type immunogens was achieved through thiol-maleimide chemistry (Figure 1A) [30]. Briefly, two C-terminally thiol-functionalized B-cell epitope branches were connected via maleimide linkages at both $\alpha$ - and $\varepsilon$-amino ends of a branched Lys core T-epitope. This allowed an efficient conjugation chemistry, optimally run at $\mathrm{pH} 6$, where thiol oxidation was essentially averted. The total absence of dimerization made possible a strictly stoichiometric use of thiol-functionalized 
peptide B epitope that, combined with fast reaction times and minimal by-product formation, led to very pure end products in a highly efficient fashion [40].

\subsubsection{Tetravalent-Branched $\mathrm{B}_{4} \mathrm{~T}$ Conjugate $\left[\mathrm{B}_{4} \mathrm{~T}(\mathrm{thi})\right]$}

The synthetic approach chosen for this construct was based on the chemoselective thioether ligation (Figure 1B) [41] of (i) the T-cell epitope, N-terminally elongated with two (cathepsin D site) plus three additional Lys residues defining a tetravalent dendrimeric core (the last two Lys residues with both $\alpha$-and $\varepsilon$-amino groups functionalized as 2-chloroacetyl derivatives); and (ii) four copies of the 19-residue VP1 B-cell epitope, acetylated at the N-terminus and C-terminally elongated with a Cys residue. While the two separately made precursors were available in highly pure form by solid phase peptide synthesis, the final thioether-based conjugation at $\mathrm{pH} 7$ was slow and unselective, requiring extensive purification to give an HPLC-homogeneous product as described earlier [29].

\subsubsection{Dimeric $\mathrm{B}_{2} \mathrm{~T}-\mathrm{TB}_{2}$ Conjugate $\left[\mathrm{B}_{2} \mathrm{~T}-\mathrm{TB}_{2}\right.$ (click)]}

A further step into chemically well-defined, single molecule vaccine platforms displaying a high number of relevant peptide motifs arranged in a dendrimeric fashion was devised by tail-to-tail fusion of two $\mathrm{B}_{2} \mathrm{~T}$ maleimide subunits via orthogonal chemical ligation by copper(I)-catalyzed azide-alkyne 1,3-cycloaddition (CuAAC), leading to a novel $\mathrm{B}_{2} \mathrm{~T}_{-} \mathrm{TB}_{2}$ multivalent platform [37] (Figure 1C). Our synthesis strategy involved preparation of functionalized peptide building blocks based on the $\mathrm{B}_{2} \mathrm{~T}(\mathrm{mal})$ predecessor but with site-specific modifications such as an extra C-terminal functionalization of the T-cell epitope with either azide- or alkyne-containing non-canonical amino acids to enable final subunit assembly. Full details on the stepwise click chemistry-based approach, including the solving of various adverse issues encountered during process optimization due to size and structural complexity of the building blocks have been extensively reported [37].

\subsection{Relevance of Dendrimer Scaffold Architecture to Immunogenicity}

To explore the impact of particular assembly patterns on immunogenic behavior, specific antiFMDV antibodies were determined by ELISA in sera at days 0, 20 (first dose), and 40 (second dose) post-immunization (pi) from mice immunized with the synthetic dendrimeric conjugates depicted in Figure 1. All peptides elicited consistent, comparable IgG titers [3.7 $\pm 0.4,3.2 \pm 0.4$ and $3.5 \pm 0.2$ for $\mathrm{B}_{2} \mathrm{~T}(\mathrm{mal}), \mathrm{B}_{4} \mathrm{~T}(\mathrm{thi})$, and $\mathrm{B}_{2} \mathrm{~T}_{-} \mathrm{TB}_{2}$ (click), respectively] after the first dose (Figure $\left.2 \mathrm{~A}\right)$. Titers were boosted up, with some differences among groups, after a second dose. The largest increase in anti-FMDV titers after boost was recorded in mice given the $\mathrm{B}_{2} \mathrm{~T}_{-} \mathrm{TB}_{2}$ (click) immunogen $(5.1 \pm 0.3)$. The other two groups showed lower post-boosting titers: $4.6 \pm 0.4\left[\mathrm{~B}_{2} \mathrm{~T}(\mathrm{mal})\right]$ and $3.9 \pm 0.3\left[\mathrm{~B}_{4} \mathrm{~T}(\mathrm{thi})\right]$. Therefore, in general terms $\mathrm{B}_{2} \mathrm{~T}_{-} \mathrm{TB}_{2}$ (click) dimer appears to elicit more anti-FMDV antibodies than its $\mathrm{B}_{2} \mathrm{~T}(\mathrm{mal})$ constituent or the other tetravalent construct, $\mathrm{B}_{4} \mathrm{~T}(\mathrm{thi})$. Likewise, after boosting, significant virus neutralizing titers (VNT) were obtained at day 40 pi in sera from all mice (Figure 2B). Again, as with IgG titers above, $\mathrm{B}_{2} \mathrm{~T}_{-} \mathrm{TB}_{2}$ (click) showed higher VNT values $(2.7 \pm 0.2)$ compared to the two other constructs: $2.0 \pm 0.5$ $\left[\mathrm{B}_{2} \mathrm{~T}(\mathrm{mal})\right]$ and $1.7 \pm 1.0\left[\mathrm{~B}_{4} \mathrm{~T}(\mathrm{thi})\right]$.

These results with three different conjugates clearly demonstrate that size, chemistry, flexibility, shape, and architecture play a crucial role, especially when considering in vivo immunogenicity of vaccine candidates whose structural differences may induce changes in the immunogen presentation and distribution, which in turn are responsible for their biological activity. These results are in agreement with previous work reporting that multimerization of B-cell epitopes enhances the responsiveness of B-cells for subsequent antibody production [42]. In terms of anti-FMDV immune response, the most active immunogen is the $\mathrm{B}_{2} \mathrm{~T}-\mathrm{TB}_{2}$ (click) construct, whose particular three-dimensional branched structure may favor a suitable arrangement that maximizes multivalent interactions with cells involved in the immune response. In sum, our work shows how subtle changes in the spatial arrangement of constructions displaying identical epitope motifs, and even maintaining the same B-cell epitope multiplicity (i.e., $\mathrm{B}_{4} \mathrm{~T}\left(\right.$ thi) vs. $\mathrm{B}_{2} \mathrm{~T}_{-} \mathrm{TB}_{2}$ (click)), may substantially modify the biological response. 
A)

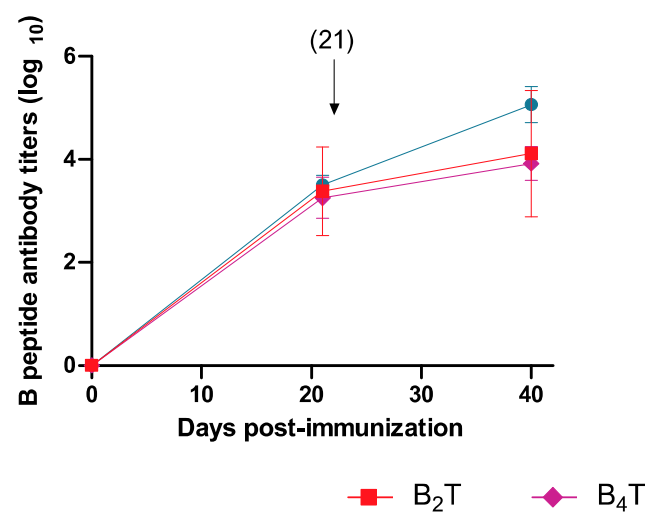

B)

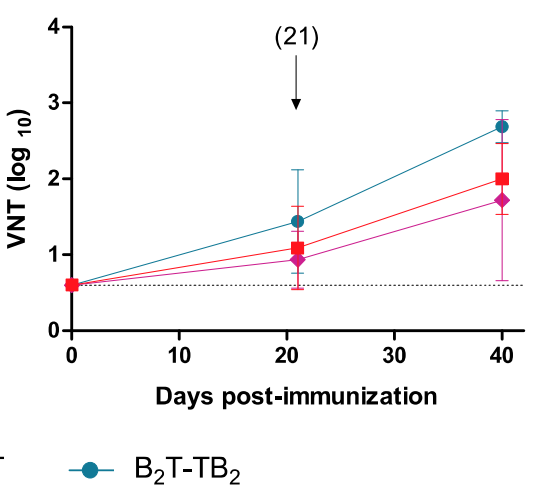

Figure 2. Anti-FMDV antibody responses of mice vaccinated with conjugates $\mathrm{B}_{2} \mathrm{~T}(\mathrm{mal}), \mathrm{B}_{4} \mathrm{~T}(\mathrm{thi})$, and $\mathrm{B}_{2} \mathrm{~T}_{-} \mathrm{TB}_{2}$ (click). (A) ELISA-determined anti-B peptide response in sera collected at the indicated days post-immunization. Each point depicts mean antibody titers \pm SD for each group. Arrow shows the day of boost. (B) Neutralizing (VNT) antibody responses at days 21 (pre-boost) and 40 (post-boost) pi. Dotted line indicates the detection limit. Each symbol represents the value for an individual mouse. Horizontal lines indicate the geometric mean for each animal group. No individual spontaneous reactivity was observed in the titers determined at day 0 . Differences were not statistically significant.

\subsection{Immunogenicity of $B_{2} T-T B_{2}$ in Pigs: Dose Effect and Long-Term Response}

To evaluate the long-term immune response elicited by our novel $\mathrm{B}_{2} \mathrm{~T}_{-} \mathrm{TB}_{2}$ (click) construct in a comparable way to the well-established $\mathrm{B}_{2} \mathrm{~T}(\mathrm{mal})$ vaccine prototype [32], domestic pigs in three different groups of four animals each were immunized and boosted with $2 \mathrm{mg}$ - the same amount used in previous studies-of $\mathrm{B}_{2} \mathrm{~T}(\mathrm{mal})$ or $\mathrm{B}_{2} \mathrm{~T}_{-} \mathrm{TB}_{2}$ (click), and $0.5 \mathrm{mg}$ of $\mathrm{B}_{2} \mathrm{~T}-\mathrm{TB}_{2}$ (click), a four-times lower dose. Two control pigs were inoculated with PBS (data not shown). In this vaccination trial, the booster was delayed to day $39 \mathrm{pi}$, to evaluate in more detail the early response. Specific anti-FMDV antibodies were determined by ELISA in pig sera at different days post-immunization. A consistent, long-lasting response was observed in all the immunized animals from day 14 pi (Figure 3A). Antibody titers in all tested groups were high, reaching ca. 4 log units, and were maintained up to day 154 pi (5 months pi). Both 2 and $0.5 \mathrm{mg}$ doses of $\mathrm{B}_{2} \mathrm{~T}-\mathrm{TB}_{2}$ (click) peptide elicited consistent and comparable IgG titers at early days [3.7 \pm 0.1 and $3.4 \pm 0.5$, respectively at day 14 pi], remaining similar in both $\mathrm{B}_{2} \mathrm{~T}_{-} \mathrm{TB}_{2}$ (click) immunized groups longitudinally [ $4.3 \pm 0.5(2 \mathrm{mg})$ and $4.2 \pm 0.6(0.5 \mathrm{mg})$ at day 154 pi] (Figure 3A). No specific anti-FMDV antibodies were detected in control non-immunized animals (data not shown).

Significant virus neutralization test (VNT) titers were also noticed from day $14 \mathrm{pi}$, with an increase observed in all animals upon boosting (day 39 pi) (Figure 3B). Interestingly, by day 154 pi, average VNT titers similar to those observed before boost were detected ( 17 weeks post-booster). As expected, control animals did not show any specific humoral response. Taken together, these results demonstrate that administration of a reduced $0.5 \mathrm{mg}$ dose of our novel $\mathrm{B}_{2} \mathrm{~T}_{-}-\mathrm{TB}_{2}$ (click) conjugate can elicit in swine long-lasting FMDV-neutralizing antibodies and consistent T-cell responses.

The specific $\mathrm{T}$-cell responses elicited by $\mathrm{B}_{2} \mathrm{~T}(\mathrm{mal})$ peptide and its homodimer $\mathrm{B}_{2} \mathrm{~T}_{-}-\mathrm{TB}_{2}$ (click), at several days pi were determined by ELISPOT analysis of the IFN- $\gamma$ - expressing PBMCs. High frequencies of spot-forming cells were found already at day $14 \mathrm{pi}$ in pigs immunized with both dendrimers at the same $2 \mathrm{mg}$ dose, in response to in vitro recall with the corresponding $\mathrm{B}_{2} \mathrm{~T}(\mathrm{mal})$ or $\mathrm{B}_{2} \mathrm{~T}_{-}-\mathrm{TB}_{2}$ (click) peptides [458.3 \pm 326.2 and $687.3 \pm 236.2$, respectively] (Figure 3C). Remarkably, significant responses were still observed in all immunized animals upon boost at day 39 pi, and up to day 154 pi. On average, pigs given $B_{2} T_{-}-B_{2}$ (click) showed higher frequencies of IFN- $\gamma$-expressing PBMCs than those receiving just $\mathrm{B}_{2} \mathrm{~T}(\mathrm{mal})$ over the long assay timespan, even using a reduced dose of $0.5 \mathrm{mg}$. Moreover, PBMC stimulations with the T-epitope peptide alone (i.e, not elongated with any Lys core) paralleled those observed with the corresponding dendrimer constructs (Figure 3D), 
confirming the recognition of $3 \mathrm{~A}(21-35)$ as a T-cell epitope by porcine lymphocytes. All the responses were specific, as no peptide-driven IFN- $\gamma$-producing cells were detected in the nonimmunized pigs (data not shown).
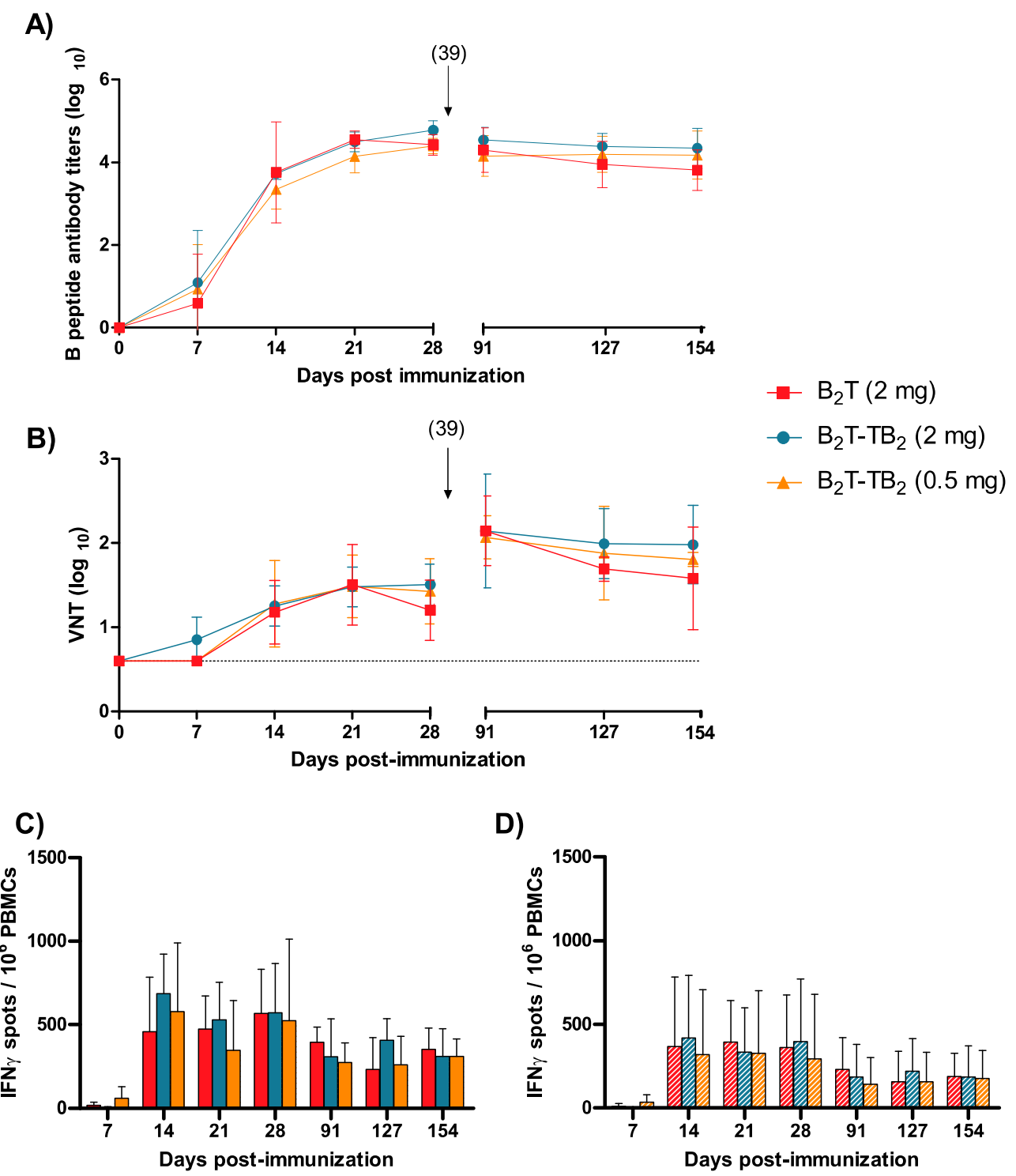

Figure 3. Long-term response and dose effect of $\mathrm{B}_{2} \mathrm{~T}-\mathrm{TB}_{2}$ (click) dimer. Time-course of the specific immune responses against FMDV in pig sera collected on the indicated days post-immunization (7, 14, 21, 28, 91, 127, and 154 pi). (A) Antibody response analyzed by ELISA. Each point depicts mean antibody titers (calculated as described in Experimental Section) \pm SD for each group of pigs. (B) Virus neutralization titers expressed as the reciprocal $\log 10$ of the last serum dilution that neutralized 100 TCID50 of FMDV O UKG/11/2001. Each symbol represents the value for an individual pig. Horizontal lines indicate the geometric mean for each animal group. Differences were not statistically significant. Arrows show the day of boost and dotted line indicates the detection limit. (C,D) Specific T-cell responses measured by an ex vivo IFN- $\gamma$ ELISPOT. IFN- $\gamma$ released by PBMCs from pigs stimulated in vitro with the corresponding dendrimer (solid bars) or with T-epitope (striped bars), respectively. The frequency of FMDV-specific IFN- $\gamma$ secreting cells was determined as detailed in Experimental Section. 


\section{Conclusions}

In this study we have assessed the close relationship between dendrimer architecture and biological response in a realistic infectious disease scenario by means of in vivo animal studies with multi-epitope peptide vaccines against FMDV. We have also reported on the main aspects [discussed in further detail in [37]] of the refinement of our synthetic methodologies and their biological impact. Specifically, dendrimers bearing same B- and T-cell epitopes from FMDV O UKG/11/2001 (an isolate belonging to FMDV/Type O/PanAsia-1 topotype responsible for the pandemic in Asia, extended to parts of Africa and Europe in 1998-2001), in different arrangements and made by diverse conjugation approaches, were explored in search of an improved FMDV vaccine candidate. These include: (i) our original tetravalent $\mathrm{B}_{4} \mathrm{~T}$ (thi) candidate with four copies of the B-epitope and one T-epitope centrally attached to a lysine core matrix by conventional thioether ligation; (ii) the optimized $\mathrm{B}_{2} \mathrm{~T}(\mathrm{mal})$ prototype, a downsized version relative to $\mathrm{B}_{4} \mathrm{~T}$, with only two copies of the B-cell epitope attached to the T-epitope through maleimide linkages; this is shown as particularly advantageous, not only in terms of immune response but also regarding chemical simplicity, conjugation reaction rates and yields; and (iii) the $\mathrm{B}_{2} \mathrm{~T}_{-} \mathrm{TB}_{2}$ (click) construct, a vaccine platform of substantial size ( 120 residues, $\left.\mathrm{MW} \sim 14.5 \mathrm{kDa}\right)$ providing tetra- and bivalent display of B- and T-cell epitopes, respectively, achieved by a combination of thiol-maleimide ligation and $\mathrm{CuAAC}$ cycloaddition. All these immunogens were administered first in mice and shown capable of inducing specific total IgGs and neutralizing antibodies in different levels. Besides, the immune response and protection elicited by our novel $\mathrm{B}_{2} \mathrm{~T}_{-} \mathrm{TB}_{2}$ (click) construct was studied in detail in pigs, a main natural FMDV host, with regard to the induction of long-term protective immune responses as well as the potential of reducing peptide dose, both important requirements for an efficient vaccine candidate. While these experiments were performed using outbred domestic pigs with different individual genetic backgrounds, the levels of animal-to-animal variation did not exceed those observed in other related studies [32].

This is, as far as we know, one of very few comparative studies on multivalent presentations of peptide epitopes from FMDV to the immune system [43-46]. In this work, all dendrimeric versions of the immunogens tested elicited antibodies against FMDV O UKG/11/2001. Interestingly, we have observed a trend toward higher antibody titers in animal groups immunized with our new homodimer $\mathrm{B}_{2} \mathrm{~T}-\mathrm{TB}_{2}$ (click). Furthermore, we have shown that these high titers of neutralizing antibodies, which can be considered as protective according to previous results with $\mathrm{B}_{2} \mathrm{~T}$ immunized and challenged pigs [32,47], can be maintained at long term. Moreover, less amount of $\mathrm{B}_{2} \mathrm{~T}_{-} \mathrm{TB}_{2}(\mathrm{click})$ immunogen can elicit consistent anti-FMDV immune responses, reducing the possible costs associated with vaccine manufacturing. Therefore, this functionally versatile and highly immunoeffective peptide-based multiepitopic vaccine defines a valuable approach to vaccine candidates with multiple applications based on similar architectures. Further studies are under way to confirm the protective responses in pigs after viral challenge, as well as to elucidate the structure-function relationships of these dendritic bioconjugates and their immunogenicity. That will allow for a high degree of control over scaffold geometry that can help develop candidates with optimized architecture, facilitate targeted delivery, and improve efficacy of peptide-based subunit vaccines.

Author Contributions: Conception, design and funding of the work (E.B., F.S. and D.A.). Data acquisition and analysis (S.D., M.F., R.C.-A., P.d.L., M.J.B., and M.R.-P.). Interpretation of data for the work (S.D., M.F., R.C.-A., P.d.L., E.B., F.S., and D.A.). Drafting the work (S.D., M.F., R.C.-A., P.d.L., F.S., and D.A.). Revising the data critically for important intellectual content (D.A., E.B., and F.S.). All authors have read and agreed to the published version of the manuscript.

Funding: This research was funded by Spanish Ministry of Science, Innovation and Universities grants AGL2014-48923-C2 and AGL2017-84097-C2-2-R (to D.A. and F.S.), and AGL2016-349 76445-R to E.B., as well as by Comunidad de Madrid co-financed ECFEDER funds (S2013/ABI-350 2906-PLATESA and P2018/BAA-4370 to F.S. and E.B.), and by Generalitat de Catalunya (2009SGR492 to D.A.). Work at Centro de Biología Molecular "Severo Ochoa" and at UPF was supported by Fundación Ramón Areces and by the Maria de Maeztu Program of the Spanish Ministry of Science, Innovation and Universities, respectively. R.C.-A. and M.F. were holders of a PhD fellowship from the Spanish Ministry of Science, Innovation and Universities (FPI program). 
Acknowledgments: We thank the staff of the CBMSO and the INIA animal facilities for their assistance.

Conflicts of Interest: The authors declare no conflict of interest.

\section{References}

1. Grubman, M.J.; Baxt, B. Foot-and-mouth disease. Clin. Microbiol. Rev. 2004, 17, 465-493. [CrossRef] [PubMed]

2. Geale, D.W.; Barnett, P.V.; Clarke, G.W.; Davis, J.; Kasari, T.R. A Review of OIE Country Status Recovery Using Vaccinate-to-Live Versus Vaccinate-to-Die Foot-and-Mouth Disease Response Policies II: Waiting Periods After Emergency Vaccination in FMD Free Countries. Transbound. Emerg. Dis. 2015, 62, 388-406. [CrossRef] [PubMed]

3. Mahy, B.W. Introduction and history of foot-and-mouth disease virus. Curr. Top. Microbiol. Immunol. 2005, 288, 1-8. [CrossRef] [PubMed]

4. Purcell, A.W.; McCluskey, J.; Rossjohn, J. More than one reason to rethink the use of peptides in vaccine design. Nat. Rev. Drug Discov. 2007, 6, 404-414. [CrossRef] [PubMed]

5. Shahriari, A.; Habibi-Pirkoohi, M. Developing Vaccines Against Foot-and-Mouth Disease: A Biotechnological Approach. Arch. Razi Inst. 2018, 73, 1-9. [CrossRef]

6. James, A.D.; Rushton, J. The economics of foot and mouth disease. Rev. Sci. Tech. Off. Int. Des. Epizoot. 2002, 21, 637-644. [CrossRef]

7. Robinson, L.; Knight-Jones, T.J.; Charleston, B.; Rodriguez, L.L.; Gay, C.G.; Sumption, K.J.; Vosloo, W. Global Foot-and-Mouth Disease Research Update and Gap Analysis: 3-Vaccines. Transbound. Emerg. Dis. 2016, 63 (Suppl. 1), 30-41. [CrossRef]

8. Sakamoto, K.; Yoshida, K. Recent outbreaks of foot and mouth disease in countries of east Asia. Rev. Sci. Tech. Off. Int. Des. Epizoot. 2002, 21, 459-463. [CrossRef]

9. Skwarczynski, M.; Toth, I. Peptide-based synthetic vaccines. Chem. Sci. 2016, 7, 842-854. [CrossRef]

10. Hos, B.J.; Tondini, E.; van Kasteren, S.I.; Ossendorp, F. Approaches to Improve Chemically Defined Synthetic Peptide Vaccines. Front. Immunol. 2018, 9, 884. [CrossRef]

11. Malonis, R.J.; Lai, J.R.; Vergnolle, O. Peptide-Based Vaccines: Current Progress and Future Challenges. Chem. Rev. 2019, 120, 3210-3229. [CrossRef] [PubMed]

12. Pfaff, E.; Mussgay, M.; Bohm, H.O.; Schulz, G.E.; Schaller, H. Antibodies against a preselected peptide recognize and neutralize foot and mouth disease virus. EMBO J. 1982, 1, 869-874. [CrossRef] [PubMed]

13. Bittle, J.L.; Houghten, R.A.; Alexander, H.; Shinnick, T.M.; Sutcliffe, J.G.; Lerner, R.A.; Rowlands, D.J.; Brown, F. Protection against foot-and-mouth disease by immunization with a chemically synthesized peptide predicted from the viral nucleotide sequence. Nature 1982, 298, 30-33. [CrossRef] [PubMed]

14. DiMarchi, R.; Brooke, G.; Gale, C.; Cracknell, V.; Doel, T.; Mowat, N. Protection of cattle against foot-and-mouth disease by a synthetic peptide. Science 1986, 232, 639-641. [CrossRef]

15. Wang, C.Y.; Chang, T.Y.; Walfield, A.M.; Ye, J.; Shen, M.; Chen, S.P.; Li, M.C.; Lin, Y.L.; Jong, M.H.; Yang, P.C.; et al. Effective synthetic peptide vaccine for foot-and-mouth disease in swine. Vaccine 2002, 20, 2603-2610. [CrossRef]

16. Acharya, R.; Fry, E.; Stuart, D.; Fox, G.; Rowlands, D.; Brown, F. The three-dimensional structure of foot-and-mouth disease virus at 2.9 A resolution. Nature 1989, 337, 709-716. [CrossRef]

17. McCullough, K.C.; De Simone, F.; Brocchi, E.; Capucci, L.; Crowther, J.R.; Kihm, U. Protective immune response against foot-and-mouth disease. J. Virol. 1992, 66, 1835-1840. [CrossRef]

18. Bixler, G.S., Jr.; Eby, R.; Dermody, K.M.; Woods, R.M.; Seid, R.C.; Pillai, S. Synthetic peptide representing a T-cell epitope of CRM197 substitutes as carrier molecule in a Haemophilus influenzae type B (Hib) conjugate vaccine. Adv. Exp. Med. Biol. 1989, 251, 175-180. [CrossRef]

19. Balz, K.; Trassl, L.; Härtel, V.; Nelson, P.P.; Skevaki, C. Virus-Induced T Cell-Mediated Heterologous Immunity and Vaccine Development. Front. Immunol. 2020, 11, 513. [CrossRef]

20. Leclerc, M.; Mezquita, L.; Guillebot De Nerville, G.; Tihy, I.; Malenica, I.; Chouaib, S.; Mami-Chouaib, F. Recent Advances in Lung Cancer Immunotherapy: Input of T-Cell Epitopes Associated With Impaired Peptide Processing. Front. Immunol. 2019, 10, 1505. [CrossRef] 
21. Garcia-Briones, M.M.; Blanco, E.; Chiva, C.; Andreu, D.; Ley, V.; Sobrino, F. Immunogenicity and T cell recognition in swine of foot-and-mouth disease virus polymerase 3D. Virology 2004, 322, 264-275. [CrossRef] [PubMed]

22. Gao, F.S.; Zhai, X.X.; Jiang, P.; Zhang, Q.; Gao, H.; Li, Z.B.; Han, Y.; Yang, J.; Zhang, Z.H. Identification of two novel foot-and-mouth disease virus cytotoxic T lymphocyte epitopes that can bind six SLA-I proteins. Gene 2018, 653, 91-101. [CrossRef] [PubMed]

23. Liao, Y.C.; Lin, H.H.; Lin, C.H.; Chung, W.B. Identification of cytotoxic T lymphocyte epitopes on swine viruses: Multi-epitope design for universal T cell vaccine. PLoS ONE 2013, 8, e84443. [CrossRef] [PubMed]

24. Haghparast, A.; Wauben, M.H.; Grosfeld-Stulemeyer, M.C.; van Kooten, P.; Hensen, E.J. Selection of T-cell epitopes from foot-and-mouth disease virus reflects the binding affinity to different cattle MHC class II molecules. Immunogenetics 2000, 51, 733-742. [CrossRef]

25. Cubillos, C.; de la Torre, B.G.; Barcena, J.; Andreu, D.; Sobrino, F.; Blanco, E. Inclusion of a specific T cell epitope increases the protection conferred against foot-and-mouth disease virus in pigs by a linear peptide containing an immunodominant B cell site. Virol. J. 2012, 9, 66. [CrossRef]

26. Blanco, E.; Cubillos, C.; Moreno, N.; Barcena, J.; de la Torre, B.G.; Andreu, D.; Sobrino, F. B epitope multiplicity and B/T epitope orientation influence immunogenicity of foot-and-mouth disease peptide vaccines. Clin. Dev. Immunol. 2013, 2013, 475960. [CrossRef]

27. Gómara, M.J.; Girona, V.; Ercilla, G.; Reig, F.; Alsina, M.A.; Haro, I. Differences in secondary structure of HAV-synthetic peptides induced by the sequential order of T- and B-cell epitopes. Biopolymers 2001, 58, 117-128. [CrossRef]

28. Sumption, K.; Rweyemamu, M.; Wint, W. Incidence and distribution of foot-and-mouth disease in Asia, Africa and South America; combining expert opinion, official disease information and livestock populations to assist risk assessment. Transbound. Emerg. Dis. 2008, 55, 5-13. [CrossRef]

29. Cubillos, C.; de la Torre, B.G.; Jakab, A.; Clementi, G.; Borras, E.; Barcena, J.; Andreu, D.; Sobrino, F.; Blanco, E. Enhanced mucosal immunoglobulin A response and solid protection against foot-and-mouth disease virus challenge induced by a novel dendrimeric peptide. J. Virol. 2008, 82, 7223-7230. [CrossRef]

30. Blanco, E.; Guerra, B.; de la Torre, B.G.; Defaus, S.; Dekker, A.; Andreu, D.; Sobrino, F. Full protection of swine against foot-and-mouth disease by a bivalent B-cell epitope dendrimer peptide. Antivir. Res. 2016, 129, 74-80. [CrossRef]

31. Bohorquez, J.A.; Defaus, S.; Munoz-Gonzalez, S.; Perez-Simo, M.; Rosell, R.; Fraile, L.; Sobrino, F.; Andreu, D.; Ganges, L. A bivalent dendrimeric peptide bearing a T-cell epitope from foot-and-mouth disease virus protein 3A improves humoral response against classical swine fever virus. Virus Res. 2017, 238, 8-12. [CrossRef] [PubMed]

32. Canas-Arranz, R.; Forner, M.; Defaus, S.; Rodriguez-Pulido, M.; de Leon, P.; Torres, E.; Bustos, M.J.; Borrego, B.; Saiz, M.; Blanco, E.; et al. A bivalent B-cell epitope dendrimer peptide can confer long-lasting immunity in swine against foot-and-mouth disease. Transbound. Emerg. Dis. 2020, 67, 1614-1622. [CrossRef] [PubMed]

33. Tam, J.P. Synthetic peptide vaccine design: Synthesis and properties of a high-density multiple antigenic peptide system. Proc. Natl. Acad. Sci. USA 1988, 85, 5409-5413. [CrossRef]

34. Cai, H.; Zhang, R.; Orwenyo, J.; Giddens, J.; Yang, Q.; LaBranche, C.C.; Montefiori, D.C.; Wang, L.X. Multivalent Antigen Presentation Enhances the Immunogenicity of a Synthetic Three-Component HIV-1 V3 Glycopeptide Vaccine. ACS Cent. Sci. 2018, 4, 582-589. [CrossRef]

35. Zhang, Z.; Pan, L.; Ding, Y.; Zhou, P.; Lv, J.; Chen, H.; Fang, Y.; Liu, X.; Chang, H.; Zhang, J.; et al. Efficacy of synthetic peptide candidate vaccines against serotype-A foot-and-mouth disease virus in cattle. Appl. Microbiol. Biotechnol. 2015, 99, 1389-1398. [CrossRef] [PubMed]

36. Boas, U.; Heegaard, P.M. Dendrimers in drug research. Chem. Soc. Rev. 2004, 33, 43-63. [CrossRef]

37. Forner, M.; Defaus, S.; Andreu, D. Peptide-Based Multiepitopic Vaccine Platforms via Click Reactions. J. Org. Chem. 2020, 85, 1626-1634. [CrossRef]

38. Saiz, J.C.; Rodriguez, A.; Gonzalez, M.; Alonso, F.; Sobrino, F. Heterotypic lymphoproliferative response in pigs vaccinated with foot-and-mouth disease virus. Involvement of isolated capsid proteins. J. Gen. Virol. 1992, 73 Pt 10, 2601-2607. [CrossRef]

39. Van Lierop, M.J.; van Noort, J.M.; Wagenaar, J.P.; Rutten, V.P.; Langeveld, J.; Meloen, R.H.; Hensen, E.J. T cell-stimulatory fragments of foot-and-mouth disease virus released by mild treatment with cathepsin $\mathrm{D}$. J. Gen. Virol. 1994, 75 Pt 11, 2937-2946. [CrossRef] 
40. Monso, M.; de la Torre, B.G.; Blanco, E.; Moreno, N.; Andreu, D. Influence of conjugation chemistry and B epitope orientation on the immune response of branched peptide antigens. Bioconjugate Chem. 2013, 24, 578-585. [CrossRef]

41. Tam, J.P. Recent advances in multiple antigen peptides. J. Immunol. Methods 1996, 196, 17-32. [CrossRef]

42. Bachmann, M.F.; Rohrer, U.H.; Kundig, T.M.; Burki, K.; Hengartner, H.; Zinkernagel, R.M. The influence of antigen organization on B cell responsiveness. Science 1993, 262, 1448-1451. [CrossRef] [PubMed]

43. Balamurugan, V.; Kumar, R.M.; Suryanarayana, V.V. Past and present vaccine development strategies for the control of foot-and-mouth disease. Acta Virol. 2004, 48, 201-214.

44. De Avila Botton, S.; Brum, M.C.; Bautista, E.; Koster, M.; Weiblen, R.; Golde, W.T.; Grubman, M.J. Immunopotentiation of a foot-and-mouth disease virus subunit vaccine by interferon alpha. Vaccine 2006, 24, 3446-3456. [CrossRef]

45. Patch, J.R.; Pedersen, L.E.; Toka, F.N.; Moraes, M.; Grubman, M.J.; Nielsen, M.; Jungersen, G.; Buus, S.; Golde, W.T. Induction of foot-and-mouth disease virus-specific cytotoxic $\mathrm{T}$ cell killing by vaccination. Clin. Vaccine Immunol. 2011, 18, 280-288. [CrossRef] [PubMed]

46. Shao, J.J.; Wang, J.F.; Chang, H.Y.; Liu, J.X. Immune potential of a novel multiple-epitope vaccine to FMDV type Asia 1 in guinea pigs and sheep. Virol. Sin. 2011, 26, 190-197. [CrossRef]

47. Canas-Arranz, R.; Forner, M.; Defaus, S.; de Leon, P.; Bustos, M.J.; Torres, E.; Sobrino, F.; Andreu, D.; Blanco, E. A Single Dose of Dendrimer B2T Peptide Vaccine Partially Protects Pigs against Foot-and-Mouth Disease Virus Infection. Vaccines 2020, 8, 19. [CrossRef]

(C) 2020 by the authors. Licensee MDPI, Basel, Switzerland. This article is an open access article distributed under the terms and conditions of the Creative Commons Attribution (CC BY) license (http://creativecommons.org/licenses/by/4.0/). 